\title{
TOXICOLOGY
}

\author{
Eric Lemaire, ${ }^{1}$ M.D., Ph.D.; Carl Schmidt, ${ }^{2}$ M.D.; Raphael Denooz, ${ }^{3}$ Ph.D.; Corinne Charlier, ${ }^{3}$ Ph.D.; \\ and Philippe Boxho, ${ }^{1}$ M.D., Ph.D.
}

\section{Postmortem Concentration and Redistribution of Diazepam, Methadone, and Morphine with Subclavian and Femoral Vein Dissection/ Clamping}

\begin{abstract}
Postmortem redistribution (PMR) concerns blood drug concentration variations after death, depending on many factors such as sampling site and technique. In our study, we focused on sampling method. 30 cases were sampled, each at cardiac, subclavian, femoral, and popliteal sites. Targeted substances were diazepam, methadone, and morphine. Blind stick and dissection/clamping techniques were concomitantly performed at subclavian and femoral sites. Subclavian and femoral concentrations were compared according to technique used. To assess the influence of sampling technique on PMR, central/peripheral ratios were calculated depending on sampling method. Results show that drug concentrations tend to be lower when drawn from a clamped subclavian or femoral vein whereas ratios including subclavian and/or femoral blood concentration are influenced according to the technique used. In conclusion, clamping a subclavian or femoral vessel before sampling tends to result in lower drug concentrations and may influence ratios, suggesting the importance of isolating vessels from thoraco-abdominal viscera.
\end{abstract}

KEYWORDS: forensic science, forensic toxicology, postmortem redistribution, sampling site, sampling method, blind stick, dissection/clamping

Postmortem blood drug concentration depends on many factors, such as sampling site, sampling technique, postmortem interval, and amount of blood collected, while postmortem redistribution (PMR) of a substance is a complex phenomenon that refers to the site- and time-dependent variations in drug concentration occurring after death. These changes are still not entirely understood but $\mathrm{pH}$, large volume of distribution $(\mathrm{Vd})$, protein binding, bacterial breakdown, and other putrefactive processes as well as how lipophilic the compound is, all seem to play a role. It is impossible to predict the extent to which a substance will redistribute after death (1-8). Sampling from central sites (subclavian vessels and heart) tends to be more affected by PMR than peripheral sites (iliac and femoral vessels). Popliteal vessels are also peripheral sites, unexplored so far. We studied popliteal blood concentrations of diazepam, methadone, and morphine, showing that sampling from this site results in drug concentrations lower than those in cardiac, subclavian, and even femoral sampling, with significant results for the latter, suggesting that popliteal blood is less prone to postmortem redistribution $(9,10)$. The extent to which a drug is prone to postmortem redistribution

${ }^{1}$ Department of Forensic Medicine, Medico-legal Institute of the University of Liège, Liège, Belgium.

${ }^{2}$ Department of Pathology, University of Michigan, Ann Arbor, MI.

${ }^{3}$ Medico-legal Toxicology Laboratory, University Hospital - C.H.U. Sart Tilman, Liège, Belgium.

Received 20 Oct. 2015; and in revised form 8 Feb. 2016; accepted 13 Feb. 2016 is usually described by the ratio of the central (C) to peripheral (P) concentration of a drug, or $\mathrm{C} / \mathrm{P}$ ratio $(1,2,6,11,12)$. Higher ratios imply greater postmortem redistribution. Some authors suggest that the $(\mathrm{C}) /(\mathrm{P})$ ratio is not always a reliable indicator of postmortem redistribution for a particular substance and evaluated the liver to peripheral blood $(\mathrm{L} / \mathrm{P})$ ratio as a possible alternative marker of PMR $(5,13,14)$. Concerning the sampling technique, it has been suggested that clamping the femoral vessel before drawing blood may prevent possible contamination from more central sites whereas with a blind stick there may be contamination from central sites. Therefore, femoral sampling performed after dissection and clamping of the vein is currently considered the method of choice as it is theoretically less subject to postmortem redistribution as it prevents possible contamination from central sources such as iliac vessels and the inferior vena cava (1-3). This procedure results in added time to the external examination as well as additional incisions, and some medicolegal offices simply perform a blind stick femoral sample without tying off the femoral vein. Hargrove et al. (15) concluded that the blind stick method of drawing femoral blood, the easiest and least invasive as well as least time-consuming procedure, did not have significant redistribution from central sites and was of equivalent quality to a clamped femoral sample for selected drugs such as selective serotonin reuptake inhibitors (SSRI), benzodiazepines (diazepam), antihistamines, and opiates (hydrocodone). The same author also showed that there was no significant change in either clamped or unclamped femoral vein morphine concentration over time as well as at any period of 
sampling within the first $24 \mathrm{~h}$ after death in bodies kept refrigerated at $4^{\circ} \mathrm{C}(16)$. With subclavian puncture, there are publications suggesting that the subclavian vein should not be considered a strictly central site, but rather an intermediate one $(12,17)$, but we did not find any study addressing adequately the issue of subclavian sampling techniques. There are few references comparing techniques: Some authors used dissection and clamping of the vein technique, others blind stick method, and some did not mention which sampling method they used.

In this study, we sampled a number of drugs from central (heart and subclavian veins) and peripheral (femoral and popliteal veins) sites and we compared the sampling techniques for subclavian and femoral sites.

We chose drugs more commonly abused in the jurisdiction of the Medico-Legal Institute of the University of Liège, Belgium. These were diazepam, methadone, and morphine. They are also compounds subject to postmortem redistribution $(4,8,16,18-24)$. In addition, their respective pharmacological properties are of interest regarding PMR, as diazepam is a lipophilic weak base (pKa 3.4) with a low Vd (0.7-2.6 L/kg), methadone is a lipophilic base ( $\mathrm{pKa} 8.6)$ with a larger $\mathrm{Vd}(4-7 \mathrm{~L} / \mathrm{kg})$ while morphine is a hydrophilic amphoteric base (pKa 7.9, 9.6) with an intermediate $\mathrm{Vd}(2-5 \mathrm{~L} / \mathrm{kg})(25)$. The nature and small volume of distribution of diazepam suggest that the compound may not be subject to PMR. However, heart/femoral blood mean ratios greater than one are found in the literature on relatively large series $(22,24)$, indicating that site-to-site difference in diazepam concentration may be related at least partially to PMR, as complexity of PMR mechanisms is still not entirely understood.

These drugs are also of medicolegal interest because of their potential role in the death of the individual, and, perhaps, if they altered cognition before death occurred.

According to some authors, diazepam is stable in blood and tissues $(26,27)$, even with putrefaction (28), unlike other benzodiazepines $(8,28,29)$ although this can depend on specimen preservation (29), temperature (29-31), and other factors (31). Concerning the stability of morphine, some authors did not see significant changes in morphine concentrations in patient samples and stored blood even when compared with admission and postmortem blood, in some cases for days after the sample was drawn $(16,21,27,32,33)$. Other studies showed that increased storage time, temperature, and degree of putrefaction resulted in greater free morphine generation (34), whereas morphine and its glucuronides were stable in sampled postmortem blood only when stored at $-20^{\circ} \mathrm{C}(35,36)$.

\section{Methods}

In this study, 30 cases were included that came from scene investigations to the medicolegal office in Liège between November 2012 and November 2013. When possible, a urine drug screen was performed to assess the presence of the drugs of interest (Drug-Screen ${ }^{\circledR}$, nal von minden $\mathrm{GmbH}$, Regensburg/ Moers, Germany). If not, the case was selected according to history and medicolegal context like potentially ingested substances found at the scene.

Intracardiac blood (ICB), subclavian blood (SB), femoral blood (FB), and popliteal blood (PB) were drawn. Samples were always performed following the same order, and blood was successively collected from subclavian, intracardiac, femoral, and finally popliteal sites.

Cardiac blood was always sampled in the right atrium, accessed via a small chest dissection. For the subclavian and femoral vein samples, blind stick transcutaneous sampling was always performed on the left side of the body (LSB and LFB) and dissection with proximal clamping was systematically performed on the right side (RSB and RFB). Right subclavian vein dissection/clamping was performed to prevent any potential blood reflux from right cardiac chambers.

Popliteal sampling required dissection for access for each case; the popliteal vein was clamped as cephalad as possible to prevent any theoretical femoral blood reflux. After popliteal vein dissection and clamping, compression of the leg was sometimes required to obtain an adequate amount of blood for testing.

According to sampling sites, mean sampled volumes were the following: ICB $8.5 \mathrm{~mL}$ (range $4-12 \mathrm{~mL}$ ); RSB $6 \mathrm{~mL}$ (range $0.5-12 \mathrm{~mL}$ ); LSB $8.9 \mathrm{~mL}$ (range 1.5-12 mL); RFB $6.3 \mathrm{~mL}$ (range 1-12 mL); LFB $7.3 \mathrm{~mL}$ (range 1-12 mL); PB $3.6 \mathrm{~mL}$ (range $0.5-8 \mathrm{~mL}$ ).

For practical reasons, only selected psychoactive drug concentrations were quantified, namely diazepam, methadone, and morphine.

In order to avoid pre-analysis drug degradation, blood samples were collected into sodium fluoride/potassium oxalate (2\%) vials and frozen at $-20^{\circ} \mathrm{C}$ prior to analysis, always performed within the first 4-6 weeks after sampling.

To compare sample techniques, for each substance, mean subclavian and femoral concentrations were compared as follows: (right subclavian blood - RSB - dissection/clamp) - (left subclavian - LSB - blind stick) and (right femoral blood - RSB - dissection/clamp) - (left femoral - LSB - blind stick).

Because femoral blood was always sampled before popliteal blood, mean right and left popliteal blood concentrations were also compared for each substance to evaluate the influence of the technique used for femoral sampling.

To assess the influence of sample techniques on measured drug concentrations, for each substance, the average ratios of following concentrations were obtained: (intracardiac blood-ICB)/ (right subclavian blood-RSB), (intracardiac blood-ICB)/(left subclavian blood-LSB), (intracardiac blood-ICB)/(right femoral blood-RFB), (intracardiac blood-ICB)/(left femoral blood-LFB), (intracardiac blood-ICB)/(popliteal blood-PB), (right subclavian blood-RSB)/(right femoral blood-RFB), (left subclavian blood-LSB)/(left femoral blood-LFB), (right subclavian blood-RSB)/(popliteal blood-PB), (left subclavian blood-LSB)/(popliteal blood-PB), (right femoral bloodRFB)/(popliteal blood-PB) and (left femoral blood-LFB)/ (popliteal blood-PB).

\section{Quantitative Analysis}

The quantification of morphine and methadone was performed on an ultra-high pressure liquid chromatograph Acquity ${ }^{\circledR}$ coupled with a tandem mass spectrometer Quattro Premier ${ }^{\circledR}$ (Waters, Zellik, Belgium). After solid-phase extraction of the sample on Oasis $\mathrm{MCX}^{\circledR}$ (Waters, Zellik, Belgium) cartridges, the separation was performed on an Acquity HSS T3 column. The mobile phase consisted in a gradient of ammonium formate (pH 3) and acidified methanol (37).

Diazepam was analyzed in blood using a high-performance liquid chromatography with photodiode array detection (Alliance $^{\circledR}$, Waters) based on a method described by Y. Gaillard et al. (38). After a liquid-liquid extraction using a mixture of diethyl ether, dichloromethane, hexane, and n-amyl alcohol, the sample was injected on a Symmetry C8 column with phosphate buffer ( $\mathrm{pH} 3.8$ ) and acetonitrile delivered according to a gradient 
elution as mobile phase. Considering low, mean, and high concentrations, respectively, coefficients of variation $(\mathrm{CV})$ were the following: $6.02 \%, 4.00 \%$, and $3.22 \%$ for diazepam; $3.33 \%$, $5.08 \%$, and $6.41 \%$ for methadone; and $6.64 \%, 4.24 \%$, and $7.10 \%$ for morphine. A single quantitation of analytes was carried out for each sampling site. Quality and validation of each analysis were ensured through two levels of control (one internal, the other commercial) and by the use of a multipoint calibration curve ( 7 points and a blank).

\section{Statistical Analysis}

Statistical analyses were performed using SAS software (version 9.3 for windows) and R software. Normality of the distributions was checked using a Shapiro-Wilk test. A logarithmic transformation of concentrations was also used to normalize the distributions.

For each substance, mean concentrations at each site were calculated and the six sampling sites were compared with a nonparametric Friedman test. Results were considered as statistically significant at $5 \%$ level $(p<0.05)$. For the comparison of concentrations at the different sampling sites and for the comparison of mean ratios, a Bonferroni's correction $(0.05 / 6=0.0083)$ was used to consider statistically significant results $(p<0.0083)$.

\section{Comparison of Subclavian and Femoral Blood Concentrations According to Sampling Technique}

For each substance, subclavian and femoral drug concentrations were compared according to the sampling technique using a nonparametric Wilcoxon signed-rank test.

\section{Comparison of Popliteal Blood Concentrations According to Femoral Sampling Technique}

For each substance, right and left popliteal drug concentrations were compared using a nonparametric Wilcoxon signed-rank test.

\section{Mean Concentration Ratios and Influence of Subclavian and Femoral Sampling Techniques on Mean Ratios}

For each substance, drug concentration differences between sites were calculated as follows: ICB - RSB, ICB - LSB, ICB RFB, ICB - LFB, ICB - PB, RSB - RFB, LSB - LFB, RSB $\mathrm{PB}, \mathrm{LSB}-\mathrm{PB}, \mathrm{RFB}-\mathrm{PB}$ and $\mathrm{LFB}$ - PB. A nonparametric Wilcoxon signed-rank test was used to assess a significant concentration difference.

For each substance, the following ratios were calculated: ICB/ RSB, ICB/LSB, ICB/RFB, ICB/LFB, ICB/PB, RSB/RFB, LSB/ $\mathrm{LFB}, \mathrm{RSB} / \mathrm{PB}, \mathrm{LSB} / \mathrm{PB}, \mathrm{RFB} / \mathrm{PB}$, and LFB/PB. A nonparametric Wilcoxon signed-rank test was also utilized to assess a significant ratio, that is, a ratio different to 1 .

Quantitative variables were summarized by the mean, standard deviation (SD), median, minimum, and maximum. Qualitative variables were summarized by mean number $(\mathrm{N})$ and percentage $(\%)$.

\section{Results}

Table 1 shows age, sex, and average estimated postmortem interval as determined by the protocol in use by our office.

Table 2 shows targeted substances and their respective frequencies.
TABLE 1-Sex, age, and estimated postmortem interval.

\begin{tabular}{lrlr}
\hline & N & Mean \pm SD & Min-Max \\
\hline Sex & & & \\
$\quad$ Male & 23 & & \\
$\quad$ Female & 7 & & \\
Age (year) & 30 & $40.2 \pm 9.5$ & $26.8-58.2$ \\
Postmortem interval $(\mathrm{h})$ & 30 & $33.3 \pm 17.8$ & $8.5-88.0$ \\
\hline
\end{tabular}

TABLE 2-Targeted substances.

\begin{tabular}{ll}
\hline & $\mathrm{N}$ \\
\hline Diazepam & 14 \\
Methadone & 24 \\
Morphine & 17 \\
\hline
\end{tabular}

\section{Comparison of Subclavian and Femoral Blood Mean Concentrations According to Sampling Technique}

Figures 1 and 2 show, respectively, for each substance, subclavian, and femoral blood mean concentrations according to sampling technique. All concentrations are expressed in microgram per liter of blood $(\mu \mathrm{g} / \mathrm{L})$.

With subclavian blood, sampling techniques showed significantly different mean concentrations for methadone with lower mean concentrations with dissection/clamp sampling technique $(p=0.0005)$. Mean diazepam $(p=0.079)$ and morphine $(p=0.082)$ are also lower with dissection/clamp, but the difference is not statistically significant.

With femoral blood, sampling techniques are still associated with significantly different mean concentrations for methadone, with lower mean concentrations with dissection/clamp sampling technique $(p=0.030)$. Mean diazepam $(p=0.052)$ concentration is also lower with dissection/clamp but not statistically significant, whereas mean morphine concentration is lower, but not significantly, with blind stick technique $(p=0.64)$.

\section{Influence of Femoral Sampling Technique on Popliteal Blood Mean Concentrations}

Figure 3 shows right and left popliteal mean concentrations. There is no significant difference between right and left sides for any of the tested drugs, indicating that the technique used for femoral sampling has no influence on the popliteal concentrations. All concentrations are expressed in microgram per liter of blood $(\mu \mathrm{g} / \mathrm{L})$. For practical purposes and given the absence of significant difference between both popliteal sites, only mean popliteal concentrations were used to calculate mean ratios.

\section{Influence of Subclavian and Femoral Sampling Technique on Mean Concentrations and Ratios}

Figure $4(a, b, c)$ shows drug concentrations distribution with mean concentration and standard deviation ( $y$-axis) for each sampling site according to sampling technique used at subclavian and femoral sites ( $x$-axis). For methadone, ICB is shown on a separate graph from RSB, LSB, RFB, LFB, and PB, because of one significant outlier. As shown in Fig. 5, for all substances, concentrations of dissection/clamp sites (RSB and RFB) tend to decline further the sampling site is from the heart. When blind stick method is used, we see the same trend except for 

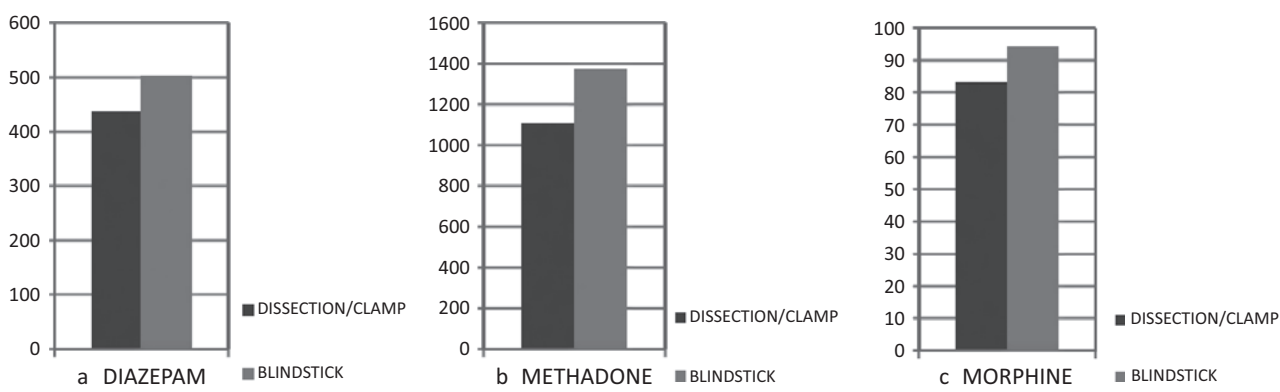

FIG. 1-Subclavian mean concentrations according to sampling technique.
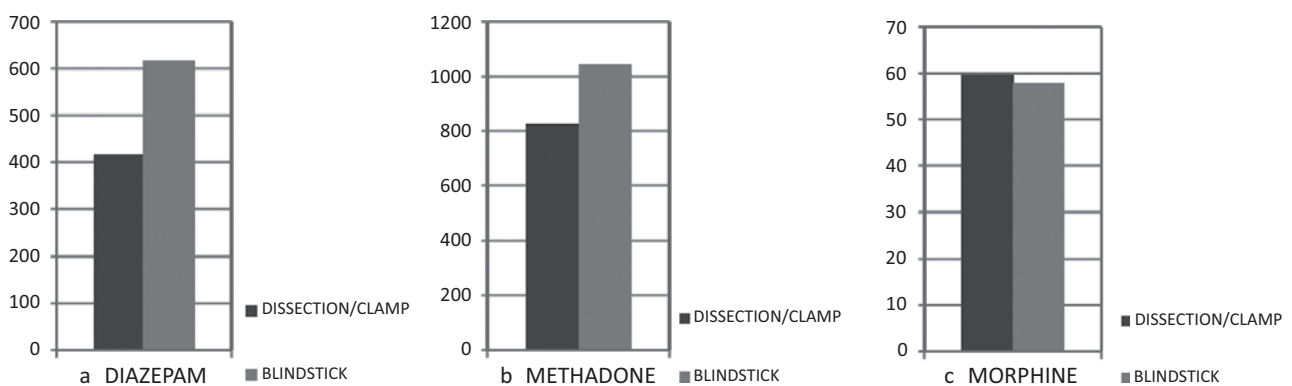

FIG. 2-Femoral mean concentrations according to sampling technique.
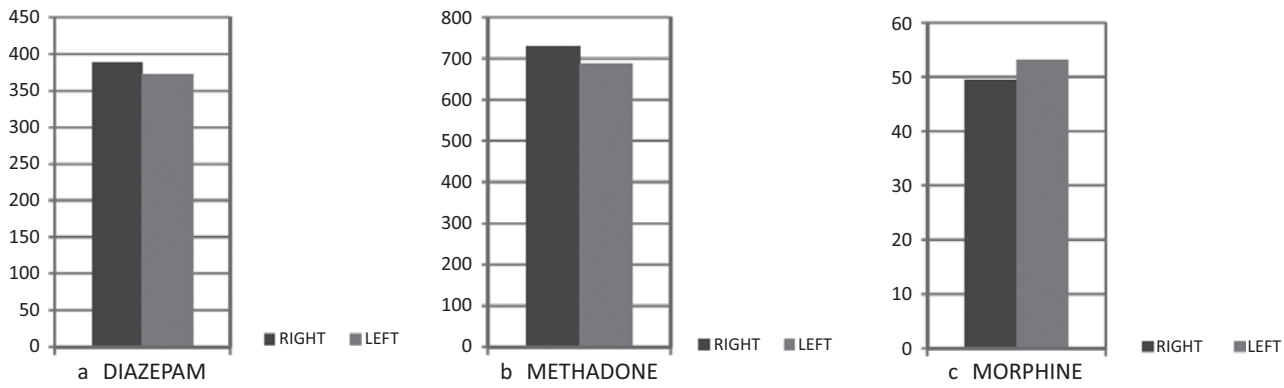

FIG. 3-Right and left popliteal mean concentrations.

diazepam, which shows higher subclavian and femoral blood concentrations. Popliteal mean concentrations are lower than other sites for all drugs and for both techniques used at subclavian and femoral sites. Furthermore, dissection/clamp subclavian and femoral mean concentrations are lower than blind stick mean concentrations, except for morphine at right femoral site where we see an opposite trend. All concentrations are expressed in microgram per liter of blood $(\mu \mathrm{g} / \mathrm{L})$.

Cardiac and subclavian sites show no significant mean concentration differences for the three compounds, and this regardless of the technique used at subclavian site; so do cardiac and femoral sites mean concentrations for both femoral sampling techniques. For methadone $(p=0.0051)$ and morphine $(p=0.0001)$, cardiac and popliteal sites show significant mean blood concentration differences. RSB and RFB show statistically significant mean concentrations differences for methadone $(p=0.0009)$ and morphine $(p=0.0041)$; RSB concentrations are consistently higher than RFB; so do LSB and LFB mean concentrations for the same substances (methadone, $p<0.0001$; morphine, $p=0.0002$ ). RSB and PB show statistically significant mean concentrations differences for morphine $(p<0.0001)$ and methadone $(p<0.0001)$; RSB concentrations are consistently higher than popliteal blood; so do LSB and PB mean concentrations for the same substances $(p<0.0001)$. RFB and PB sites show significant mean concentrations differences for methadone $(p=0.0015)$ and morphine $(p<0.0001)$ whereas LFB and PB mean concentrations are significantly different for the three drugs (diazepam $p=0.0031$, methadone $p<0.0001$, morphine $p=0.0017$ ).

To assess the occurrence of postmortem redistribution, for each substance, the average ratios of following concentrations were obtained: ICB/RSB, ICB/LSB, ICB/RFB, ICB/LFB, ICB/ $\mathrm{PB}, \mathrm{RSB} / \mathrm{RFB}, \mathrm{LSB} / \mathrm{LFB}, \mathrm{RSB} / \mathrm{PB}, \mathrm{LSB} / \mathrm{PB}, \mathrm{RFB} / \mathrm{PB}$, and LFB/PB as shown in Table 3.

Figure 6 illustrates the evolution of the mean ratios for the three compounds according to the sampling technique used at subclavian and femoral sites. ICB/RSB and ICB/RFB ratios are consistently greater than the ICB/LSB and ICB/LFB ratios, except for morphine showing ICB/RFB less than ICB/LFB mean ratio. For methadone and morphine, RSB/RFB mean ratios are less than LSB/LFB ratios whereas diazepam shows RSB/RFB mean ratio greater than $\mathrm{LSB} / \mathrm{LFB}$. For all substances, RSB/PB and $\mathrm{RFB} / \mathrm{PB}$ mean ratios are consistently less than the LSB/PB and $\mathrm{LFB} / \mathrm{PB}$ ratios except for morphine showing $\mathrm{RFB} / \mathrm{PB}$ mean ratio greater than $\mathrm{LFB} / \mathrm{PB}$. 

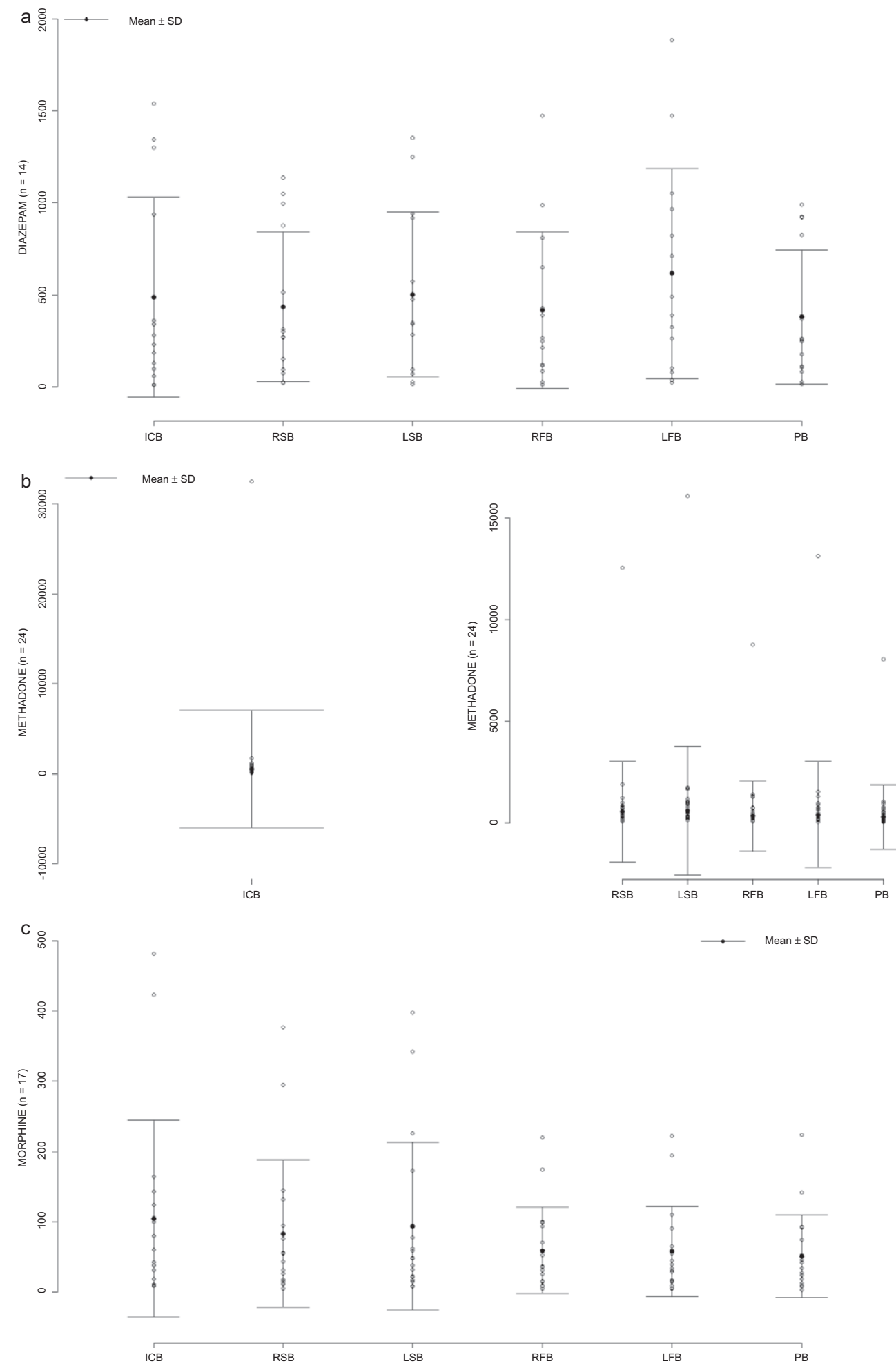

FIG. 4-(a) Diazepam mean concentrations according to sampling site and technique. (b) Methadone mean concentrations according to sampling site and technique. (c) Morphine mean concentrations according to sampling site and technique.

Intracardiac/subclavian as well as intracardiac/femoral mean ratios are not statistically significant, that is, different from 1 , for any substances and this regardless of the sampling technique used at subclavian and femoral sites. ICB/PB mean ratios are statistically greater than 1 for methadone and morphine, but are not statistically significant, that is, different from 1 , for diazepam. RSB/RFB and LSB/LFB mean ratios are statistically greater than 1 for methadone and morphine, but are not statistically significant, that is, different from 1 , for diazepam. Subclavian/popliteal as well as femoral/popliteal mean ratios are statistically significant, that is, different from 1 , for methadone and morphine, regardless of the sampling technique used at subclavian and femoral sites. For diazepam, LFB/PB is the only statistically significant, that is, different from 1 , mean ratio. 

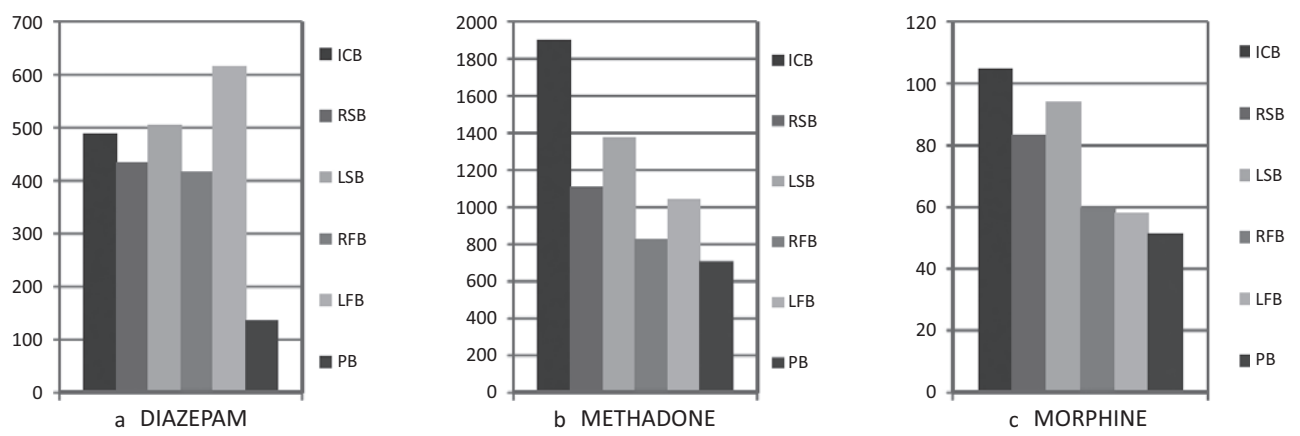

FIG. 5-Intracardiac, right and left subclavian, right and left femoral, and popliteal mean concentrations.

TABLE 3-Mean concentration ratios according to sampling techniques at subclavian and femoral sites.

\begin{tabular}{|c|c|c|c|c|c|c|c|}
\hline Substance & Ratios & $\mathrm{N}$ & Mean \pm SD & Min & Median & Max & Wilcoxon $p$-value \\
\hline \multirow[t]{11}{*}{ Diazepam } & ICB/RSB & 14 & $0.93 \pm 0.32$ & 0.45 & 0.93 & 1.35 & 0.54 \\
\hline & ICB/LSB & 14 & $0.84 \pm 0.35$ & 0.34 & 0.81 & 1.46 & 0.068 \\
\hline & ICB/RFB & 14 & $1.01 \pm 0.41$ & 0.50 & 0.91 & 2.07 & 0.46 \\
\hline & ICB/LFB & 14 & $0.75 \pm 0.38$ & 0.12 & 0.74 & 1.34 & 0.049 \\
\hline & $\mathrm{ICB} / \mathrm{PB}$ & 14 & $1.06 \pm 0.33$ & 0.46 & 1.04 & 1.58 & 0.54 \\
\hline & RSB/RFB & 14 & $1.11 \pm 0.28$ & 0.70 & 1.17 & 1.54 & 0.15 \\
\hline & LSB/LFB & 14 & $0.90 \pm 0.38$ & 0.35 & 0.87 & 1.47 & 0.36 \\
\hline & RSB/PB & 14 & $1.16 \pm 0.21$ & 0.85 & 1.15 & 1.52 & 0.02 \\
\hline & LSB/PB & 14 & $1.40 \pm 0.54$ & 0.83 & 1.28 & 2.64 & 0.011 \\
\hline & RFB/PB & 14 & $1.08 \pm 0.21$ & 0.70 & 1.05 & 1.51 & 0.22 \\
\hline & LFB/PB & 14 & $1.99 \pm 1.81$ & 0.88 & 1.46 & 7.63 & $0.0031 *$ \\
\hline \multirow[t]{11}{*}{ Methadone } & ICB/RSB & 24 & $1.11 \pm 0.65$ & 0.36 & 0.95 & 2.59 & 0.96 \\
\hline & ICB/LSB & 24 & $0.94 \pm 0.55$ & 0.23 & 0.84 & 2.38 & 0.40 \\
\hline & ICB/RFB & 24 & $1.70 \pm 1.42$ & 0.56 & 1.11 & 5.81 & 0.13 \\
\hline & $\mathrm{ICB} / \mathrm{LFB}$ & 24 & $1.50 \pm 1.25$ & 0.43 & 1.03 & 6.17 & 0.18 \\
\hline & ICB/PB & 24 & $1.91 \pm 1.38$ & 0.51 & 1.50 & 6.24 & $0.0022 *$ \\
\hline & RSB/RFB & 24 & $1.54 \pm 0.77$ & 0.66 & 1.36 & 4.07 & 0.0002* \\
\hline & LSB/LFB & 24 & $1.66 \pm 1.21$ & 0.75 & 1.30 & 6.98 & $<0.0001 *$ \\
\hline & RSB/PB & 24 & $1.74 \pm 0.73$ & 1.02 & 1.64 & 4.37 & $<0.0001 *$ \\
\hline & LSB/PB & 24 & $2.11 \pm 1.17$ & 1.00 & 1.87 & 7.07 & $<0.0001 *$ \\
\hline & RFB/PB & 24 & $1.20 \pm 0.27$ & 0.75 & 1.14 & 1.85 & $0.0005^{*}$ \\
\hline & LFB/PB & 24 & $1.35 \pm 0.29$ & 0.89 & 1.30 & 2.05 & $<0.0001 *$ \\
\hline \multirow[t]{11}{*}{ Morphine } & ICB/RSB & 17 & $1.29 \pm 0.65$ & 0.50 & 1.13 & 2.82 & 0.093 \\
\hline & ICB/LSB & 17 & $1.17 \pm 0.61$ & 0.45 & 1.06 & 2.58 & 0.55 \\
\hline & ICB/RFB & 17 & $1.67 \pm 1.09$ & 0.54 & 1.19 & 4.78 & 0.018 \\
\hline & $\mathrm{ICB} / \mathrm{LFB}$ & 17 & $1.83 \pm 1.57$ & 0.67 & 1.30 & 7.17 & 0.013 \\
\hline & $\mathrm{ICB} / \mathrm{PB}$ & 17 & $2.05 \pm 1.25$ & 0.83 & 1.55 & 5.38 & 0.0001* \\
\hline & RSB/RFB & 17 & $1.25 \pm 0.29$ & 0.81 & 1.20 & 1.78 & $0.0016 *$ \\
\hline & LSB/LFB & 17 & $1.49 \pm 0.51$ & 0.88 & 1.41 & 2.83 & $0.0001 *$ \\
\hline & RSB/PB & 17 & $1.57 \pm 0.33$ & 1.00 & 1.60 & 2.08 & $<0.0001 *$ \\
\hline & $\mathrm{LSB} / \mathrm{PB}$ & 17 & $1.81 \pm 0.62$ & 0.84 & 1.75 & 3.03 & $<0.0001 *$ \\
\hline & RFB/PB & 17 & $1.28 \pm 0.21$ & 0.98 & 1.25 & 1.63 & $<0.0001 *$ \\
\hline & LFB/PB & 17 & $1.24 \pm 0.29$ & 0.70 & 1.24 & 1.68 & $0.0069 *$ \\
\hline
\end{tabular}

Significant p-values in bold and marked with*.

\section{Discussion}

When comparing subclavian and femoral site sampling techniques, subclavian morphine mean concentrations tend to be lower when drawn from a clamped subclavian vein, but not for femoral sampling. Methadone and diazepam concentrations are lower when drawn from either clamped vein, but the results are only significant for methadone. Results for diazepam are very close to statistical significance, especially for the femoral site $(p=0.052)$. Results for morphine at the femoral site are consistent with those found in one study concerning femoral sampling technique, showing no statistical difference between clamped and unclamped femoral vessel but median concentrations higher in clamped vessel (15). On the contrary, our results suggest lower diazepam concentrations at the femoral site with dissection/clamping technique, unlike another study that found that the blind stick sample was consistently lower than the clamped sample (16). We did not find any references that looked at subclavian sampling technique. Diazepam and methadone show the same trend; that is, their respective mean concentrations are lower with dissection/clamping technique at both sites, suggesting that clamping the subclavian and femoral veins and isolating it from thoraco-abdominal blood may result in lower concentrations of these drugs, even in central sites. Morphine mean concentrations are also lower at the subclavian site with dissection/clamping technique whereas mean concentrations are slightly lower at the femoral site with the blind stick sampling method. Furthermore, differences in mean volumes sampled at subclavian and femoral sites according to the sampling technique (RSB $6 \mathrm{~mL}$; LSB $8.9 \mathrm{~mL}$; RFB $6.3 \mathrm{~mL}$; LFB $7.3 \mathrm{~mL}$ ) were 


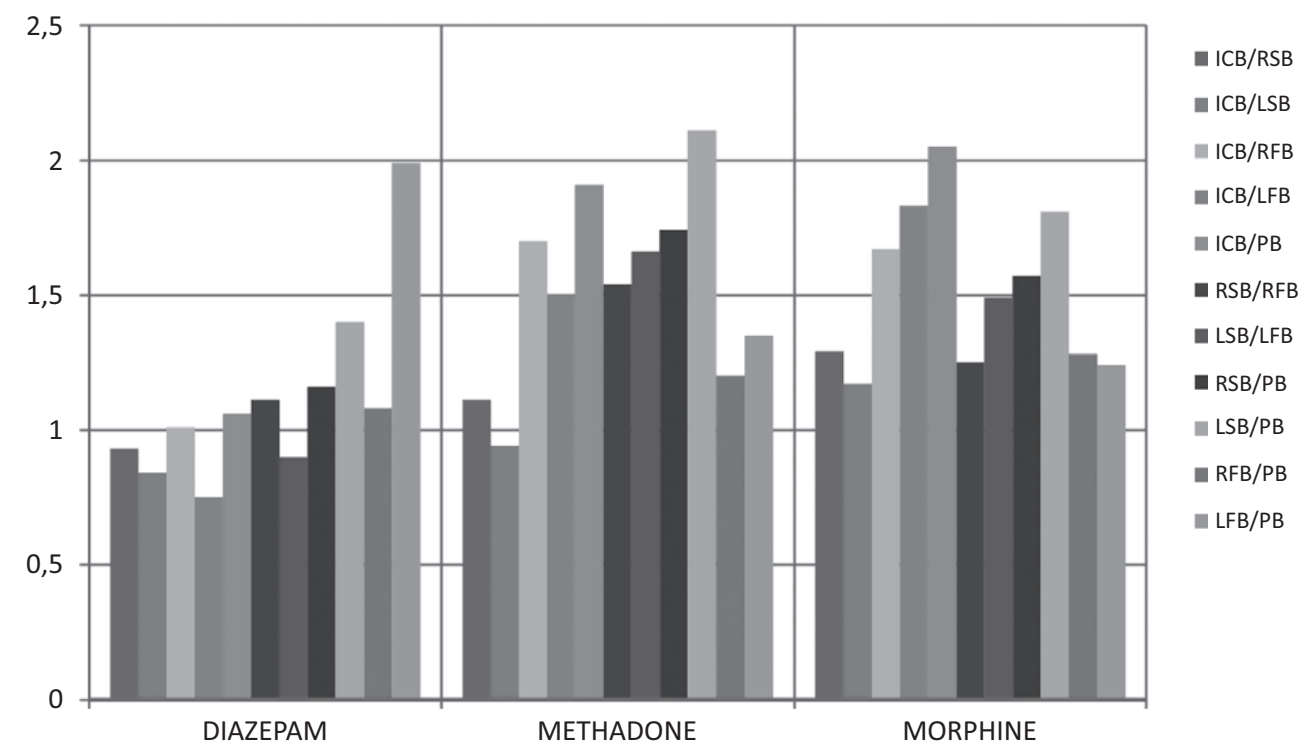

FIG. 6-Diazepam, methadone, and morphine mean ratios according to subclavian and femoral sampling techniques.

found and hence may also have contributed to the aforementioned concentrations differences as more central blood was potentially drawn with blindstick technique.

We did not find a significant difference between right and left popliteal samples, indicating that femoral sampling technique used has no influence on popliteal drug mean concentrations.

Study of the influence of sampling techniques on mean ratios shows different trends. Intracardiac/subclavian and intracardiac/ femoral mean ratios are consistently greater with dissection/ clamping sampling technique for methadone and diazepam, suggesting that dissection/clamping also results in isolation of these drugs from central PMR processes. However, mean ratios in the femoral site show the opposite trend for morphine, accounting for other possible phenomenon, like postmortem instability of morphine (34-36) depending on sampling site. There may be contamination with central abdominal blood, accounting for the increased intracardiac/femoral ratio with the femoral blind stick technique. For methadone and morphine, subclavian/femoral mean ratios are lower with the dissection/clamp technique but diazepam shows opposite results, strengthening the hypothesis that dissection/clamping of the subclavian and femoral vessels allows isolation from central redistribution, but this is not true for all drugs. Diazepam subclavian/femoral mean ratios are consistently lower with blind stick sampling, and this may be due to increased degradation of diazepam in central compartments (2931). It will be interesting to look at this in other similar drugs such as those acidic or weakly basic with a low pKa.

For all three substances, subclavian/popliteal and femoral/ popliteal ratios are consistently lower when dissection/clamping technique is used at subclavian and femoral sites, except for morphine, indicating that isolation of subclavian and femoral blood from thoraco-abdominal viscera brings mean concentrations closer to popliteal blood, but still depend on the drug sampled and the site of sampling. However, popliteal blood mean concentrations of all sampled drugs are significantly lower than those obtained in femoral blood, regardless of the femoral technique used, which means that popliteal blood is probably less prone to postmortem redistribution even than a clamped femoral vein. Unfortunately, for practical reasons, our study was limited to those compounds showing relatively low volume of distribution, and site-to-site variations may be more marked with other drugs exhibiting larger Vd.

In conclusion, our study is the first to describe a four-site sampling assessment, including the popliteal vein and using two different sampling methods at subclavian and femoral sites. Results show that drug concentrations tend to be lower when drawn from a clamped subclavian or femoral vein and may also indicate that ratios calculated with subclavian and/or femoral blood concentrations are affected by dissection/clamp technique at both sites. This may be due to the isolation of subclavian and femoral blood from central blood with clamping, but may be different with less basic drugs such as diazepam.

\section{References}

1. Pélissier-Alicot AL, Gaulier JM, Champsaur P, Marquet P. Mechanisms underlying postmortem redistribution of drugs: a review. J Anal Toxicol 2003;27(8):533-44.

2. Yarema MC, Becker CE. Key concepts in postmortem drug redistribution. Clin Toxicol 2005;43(4):235-41.

3. Cook DS, Braithwaite RA, Hale KA. Estimating antemortem drug concentrations from postmortem blood samples: the influence of postmortem redistribution. J Clin Pathol 2000;53(4):282-5.

4. Ferner RE. Post-mortem clinical pharmacology. Br J Clin Pharmacol 2008;66(4):430-43.

5. Rodda KE, Drummer OH. The redistribution of selected psychiatric drugs in post-mortem cases. Forensic Sci Int 2006;164(2-3):235-9.

6. Drummer OH. Postmortem toxicological redistribution. In: Rutty GN, editor. Essentials of autopsy practice. London, U.K.: Springer-Verlag, 2008;1-21.

7. Sastre C, Baillif-Couniou V, Musarella F, Bartoli C, Mancini J, Piercecchi-Marti MD, et al. Can subclavian blood be equated with a peripheral blood sample? A series of 50 cases. Int J Legal Med 2013;127(2):37984.

8. Drummer OH. Postmortem toxicology of drugs of abuse. Forensic Sci Int 2004;142(2-3):101-13.

9. Lemaire E, Schmidt C. Comparison of the concentrations of morphine, methadone and diazepam when sampled from cardiac, subclavian, femoral and popliteal sites and from clamped and unclamped subclavian and femoral vein samples. Proceedings of the 67th Annual Meeting American Academy of Forensic Sciences; 2015 Feb 16-21; Orlando, FL. Colorado Springs, CO: American Academy of Forensic Sciences, 2015.

10. Lemaire E, Schmidt C, Denooz R, Charlier C, Boxho Ph. Popliteal vein blood sampling and the postmortem redistribution of diazepam, methadone and morphine. J Forensic Sci 2016;61(4):1017-28. 
11. Kennedy MC. Post-mortem drug concentrations. Intern Med J 2010;40 (3):183-7.

12. Prouty RW, Anderson WH. The forensic science implications of site and temporal influences on postmortem blood-drug concentrations. J Forensic Sci 1990;35(2):243-70.

13. McIntyre IM. Liver and peripheral blood concentration ratio $(\mathrm{L} / \mathrm{P})$ as a marker of postmortem drug redistribution: a literature review. Forensic Sci Med Pathol 2014;10(1):91-6.

14. McIntyre IM, Meyer Escott C. Postmortem drug redistribution. J Forensic Res 2012;3:6.

15. Hargrove VM, McCutcheon JR. Comparison of drug concentrations taken from clamped and unclamped femoral vessels. J Anal Toxicol 2008;32 (8):621-5.

16. Hargrove VM, Molina DK. Peripheral postmortem redistribution of morphine. Am J Forensic Med Pathol 2014;35(2):106-8

17. Molina DK, Hargrove VM. Should postmortem subclavian blood be considered a peripheral or central sample? Am J Forensic Med Pathol 2013;34(2):155-8

18. Crandall CS, Kerrigan S, Blau RL, Lavalley J, Zumwalt R, McKinney $\mathrm{PE}$. The influence of site of collection on postmortem morphine concentrations in heroin overdose victims. J Forensic Sci 2006;51(2):413-20.

19. Gerostamoulos D, Beyer J, Staikos V, Tayler P, Woodford N, Drummer $\mathrm{OH}$. The effect of the postmortem interval on the redistribution of drugs: a comparison of mortuary admission and autopsy blood specimens. Forensic Sci Med Pathol 2012;8(4):373-9.

20. Han E, Kim E, Hong H, Jeong S, Kim J, In S, et al. Evaluation of postmortem redistribution phenomena for commonly encountered drugs. Forensic Sci Int 2012;219(1-3):265-71.

21. Skopp G, Lutz R, Ganssmann B, Mattern R, Aderjan R. Postmortem distribution pattern of morphine and morphine glucuronides in heroin overdose. Int J Legal Med 1996;109(3):118-24.

22. Hepler BR, Isenschmid DS, Schmidt CJ. Postmortem redistribution: practical considerations in death investigation. Proceedings of the 56th Annual Meeting of the American Academy of Forensic Sciences; 2004 Feb 16-21; Dallas, TX. Colorado Springs, CO: American Academy of Forensic Sciences, 2004.

23. Logan BK, Smirnow D. Postmortem distribution and redistribution of morphine in man. J Forensic Sci 1996;41(2):221-9.

24. Dalpe-Scott M, Degouffe M, Garbutt D, Drost MA. Comparison of drug concentrations in postmortem cardiac and peripheral blood in 320 Cases. Can Soc For Sci J 1995;28(2):113-21.

25. Baselt RC. Disposition of toxic drugs and chemicals in man, 10th edn. Seal Beach, CA: Biomedical Publications, 2014.

26. Levine B, Blanke RV, Valentour JC. Postmortem stability of benzodiazepines in blood and tissues. J Forensic Sci 1983;28(1):102-15.

27. Karinen R, Andresen W, Smith-Kielland A, Morland J. Long-term storage of authentic postmortem forensic blood samples at $-20^{\circ} \mathrm{C}$ : measure concentrations of benzodiazepines, central stimulants, opioids and certain medicinal drugs before and after storage for 16-18 years. J Anal Toxicol 2014;38:686-95.

28. Stevens HM. The stability of some drugs and poisons in putrefying human liver tissues. J Forensic Sci Soc 1984;24(6):577-89.

29. Robertson MD, Drummer OH. Postmortem drug metabolism by bacteria. J Forensic Sci 1995;40(3):382-6.

30. El Mahjoub A, Staub C. Stability of benzodiazepines in whole blood samples stored at varying temperatures. J Pharm Biomed Anal 2000;23 (6): 1057-63.

31. Skopp G, Pötsch L, König I, Mattern R. A preliminary study on the stability of benzodiazepines in blood and plasma stored at 4 degrees $\mathrm{C}$. Int J Legal Med 1998;111(1):1-5.

32. Hadidi KA, Oliver JS. Stability of morphine and buprenorphine in whole blood. Int J Legal Med 1998;111(3):165-7.

33. Gerostamoulos J, Drummer OH. Postmortem redistribution of morphine and its metabolites. J Forensic Sci 2000;45(4):843-5.

34. Carroll FT, Marraccini JV, Lewis S, Wright W. Morphine-3-D glucuronide stability in postmortem specimens exposed to bacterial enzymatic hydrolysis. Am J Forensic Med Pathol 2000;21(4): 323-9.

35. Skopp G, Pötsch L, Klingmann A, Mattern R. Stability of morphine, morphine-3-glucuronide, and morphine-6-glucuronide in fresh blood and plasma and postmortem blood samples. J Anal Toxicol 2001;25 (1):2-7.

36. Papoutsis I, Nikolaou P, Pistos C, Dona A, Stefanidou M, Spiliopoulou $\mathrm{C}$, et al. Stability of morphine, codeine, and 6-acetylmorphine in blood at different sampling and storage conditions. J Forensic Sci 2014;59 (2):550-4.

37. Dubois N, Debrus B, Hubert Ph, Charlier C. Validated quantitative simultaneous determination of cocaine, opiates and amphetamines in serum by U-HPLC coupled to tandem mass spectrometry. Acta Clin Belg 2010;65(1):75-84.

38. Gaillard Y, Pépin G. Use of high-performance liquid chromatography with photodiode array UV detection for the creation of a 600-compound library. application to forensic toxicology. J Chromatogr A 1997;763:149-63.

Additional information and reprint requests:

Eric Lemaire, M.D., Ph.D.

Department of Pathology

University Hospital - C.H.U. Sart Tilman, Liège, Belgium

Domaine du Sart-Tilman - B.35

B-4000 Liège

Belgium

E-mail: eric.lemaire@chu.ulg.ac.be 